\title{
Influência da infecção experimental com Cryptosporidium baileyi na resposta imune de frangos de corte vacinados contra a doença de Newcastle
}

\author{
Influence of experimental infection with Cryptosporidium baileyi on the \\ immune response of broiler chickens to Newcastle disease \\ vaccination
}

Marcelo Vasconcelos Meireles ${ }^{1}$, Antonio Carlos Paulillo², Giane Serafim da Silva ${ }^{3}$, Alvimar José da Costa ${ }^{2}$, Maria Cecília Rui Luvizotto', Luciano Doretto Júnior ${ }^{4}$, Fernando Antonio de Ávila ${ }^{5}$

\section{Resumo}

Frangos de corte, criados em gaiolas, foram inoculados, respectivamente, por via oral/intratraqueal e ocular, com diferentes doses de oocistos de Cryptosporidium baileyie vírus vacinal da doença de Newcastle, para análise de lesões macro e microscópicas e para avaliação da influência do parasito na imunidade das aves, adotando como modelo a doença de Newcastle. Foram empregadas 128 aves, distribuídas em oito tratamentos e quatro repetições com quatro aves por parcela. Aos dez dias de idade procedeu-se à inoculação dos animais, via oral/ intratraqueal, com $10^{3}, 10^{5}$ e $10^{7}$ oocistos, seguida da vacinação, no $14^{\circ}$ dia de vida, com a amostra LaSota, do vírus da doença de Newcastle (VDN). Para análise da resposta imune, foram utilizados os resultados dos títulos de anticorpos inibidores da hemaglutinação $(\mathrm{HI})$, com posterior desafio frente a uma estirpe velogênica viscerotrópica, do VDN, aos 43 dias de vida das aves. Foi também realizada a análise de lesões macro e microscópicas na traquéia e bursa de Fabricius das aves aos 42 dias de vida. Os grupos inoculados com o $C$. baileyi apresentaram, na bursa de Fabricius, lesões caracterizadas por leve hiperemia e exsudato caseoso preenchendo à luz desse órgão atrofia leve e infiltração de linfócitos e plasmócitos na lâmina própria. Na traquéia dos grupos inoculados com o parasito, via intratraqueal, havia a presença de muco e leve hiperemia, hiperplasia epitelial e de folículos linfóides na submucosa. Os resultados referentes ao desafio e títulos de anticorpos $\mathrm{HI}$ mostraram que não houve interferência da infecção pelo $C$. baileyina resposta imune das aves.
Palavras chave: Cryptosporidium baileyi;frangos de corte; imunidade

\section{Introdução}

A infecção natural em aves pelo Cryptosporidium baileyi apresenta hoje uma distribuição mundial, com relatos da localização do parasito no trato respiratório, intestinal e bursa de Fabricius (Dhillon et al., 1981; Randall, 1982; Itakura et al., 1984; Goodwin et al., 1988; Papadopoulou et al., 1988; Fernández et al., 1990).

No trato respiratório, o C. baileyicausa doença clínica com presença de sinais como espirros, dificuldade respiratória e ronqueira, além de lesões macro e microscópicas características de traqueíte, pneumonia e aerosaculite (Blagburn et al., 1987; Lindsay et al., 1988).

A infecção pelo $C$. baileyina bursa de Fabricius geralmente é subclínica, sem o desenvolvimento de lesões macroscópicas (Blagburn et al., 1987; Levy et al., 1988).

Pintos livres de patógenos específicos, respectivamente, aos quatro e cinco dias de idade, foram inoculados com cepa vacinal da doença de Gumboro e/ou C. baileyi (Levy et al., 1988). Nesse experimento, aos 8 e 16 dias após a inoculação, a infecção conjunta com ambos os agentes resultou em um efeito sinérgico na atrofia dos folículos linfóides da bursa de Fabricius.

Blagburn et al. (1987), pesquisando a influência do $C$. baileyi na resposta imune de frangos de corte vacinados contra a doença de Newcastle, não encontraram interferência do parasito na produção de anticorpos induzida pela vacina inativada, mas sim na hipersensibilidade tardia medida por inoculação de tuberculina na barbela de aves infectadas, via intratraqueal.

\footnotetext{
Apoio financeiro: Fundação de Amparo à Pesquisa do Estado de São Paulo-FAPESP

1 Departamento de Clínica, Cirurgia e Reprodução Animal, Curso de Medicina Veterinária, FOA, UNESP, Campus de Araçatuba e Pósgraduando, Curso de Pós-graduação em Zootecnia, FCAVJ, UNESP, Bolsista da CAPES

2 Departamento de Patologia Veterinária, Faculdade de Ciências Agrárias e Veterinárias, UNESP, Campus de Jaboticabal (FCAVJ, UNESP), Bolsista do CNPq

3 Pós-Graduanda, Curso de Pós-graduação em Zootecnia, FCAVJ, UNESP, Bolsista da FAPESP

${ }^{4}$ Pós-graduando, Curso de Pós-graduação em Patologia Animal, FCAVJ, UNESP, LARA, Campinas

${ }^{5}$ Departamento de Microbiologia, FCAVJ, UNESP, Bolsista do CNPq
} 
Considerando que o significado da infecção no intestino e/ou bursa de Fabricius permanece ainda indefinido para a maioria das espécies aviárias, delineou-se o presente trabalho que teve como objetivo estudar a influência da infecção por uma cepa de $C$. baileyi, isolada no Estado do Rio de Janeiro (Meireles e Figueiredo, 1992), na resposta imune de frangos de corte, adotando como modelo a doença de Newcastle.

\section{Material e Métodos}

Aves experimentais, instalações, manejo e nutrição das aves - Foram utilizados 128 pintos de corte, machos, da linhagem Hubbard, agrupados com base no peso para formação de parcelas homogêneas e distribuídos, aleatoriamente, em oito tratamentos (grupos) e quatro repetições com quatro aves por parcela.

As aves em sua fase inicial (1-28 dias) foram alojadas em baterias com aquecimento elétrico. O alojamento na fase final (29-42 dias) foi em gaiolas de recria, permanecendo quatro aves por unidade de gaiola.

As aves foram alimentadas com ração comercial (isenta de drogas anticoccidianas) compatível com as diferentes fases do seu ciclo de vida e submetidas às condições de manejo usual em avicultura.

Aos $10^{\circ}$ e $14^{\circ}$ dias de vida, as aves receberam os inóculos de acordo com a Tabela 1.

Para análise da resposta imune, no sistema doença de Newcastle, foram utilizados os resultados dos títulos de anticorpos inibidores da hemaglutinação $(\mathrm{HI})$, com posterior desafio frente a um vírus virulento.

Obtenção e padronização dos oocistos do $C$. baileyi - A amostra do C. baileyi empregada, isolada no Estado do Rio de Janeiro (Meireles e Figueiredo, 1992), foi obtida junto ao laboratório de Ornitopatologia do curso de Medicina Veterinária da UNESP, Campus de Araçatuba.

Esses oocistos foram inoculados diretamente no inglúvio de pintos de dois dias de idade, para multiplicação do parasito. As fezes dessas aves foram colhidas do $8^{\circ}$ ao $13^{\circ}$ dia após a inoculação, coadas em peneiras e armazenadas em bicromato de potássio a $2,5 \%$ a $4^{\circ} \mathrm{C}$.

Posteriormente, os oocistos foram concentrados pelo método de Arrowood e Sterling (1987) com algumas modificações. Foram utilizadas soluções de açúcar em diferentes concentrações, preparadas a partir de uma solução mãe saturada de açúcar (320 ml de água, $500 \mathrm{~g}$ de açúcar e $9 \mathrm{ml}$ de fenol). Dessa solução, foi preparada uma solução $(A)$ na diluição de $1: 2$ e outra solução $B$ na diluição de 1:4. Em um tubo de centrífuga, com capacidade de $100 \mathrm{ml}$, foram adicionados $30 \mathrm{ml}$ da solução $A$ e sobre a mesma $30 \mathrm{ml}$ da solução $B$. Uma alíquota de 15 $\mathrm{ml}$ das fezes diluídas em bicromato de potássio foi adicionada sobre a solução $B$. Os tubos foram centrifugados a 2.000 RPM por 30 min.; após, foi colhida a parte correspondente à solução $B$, que foi diluída em água, com posterior centrifugação a 2.000 RPM por 10 min. e colhido o sedimento que foi submetido novamente ao mesmo processo de concentração e purificação descrito.

Após esse processo, os oocistos foram "esterilizados" com uma solução de hipoclorito de sódio a $10 \%$ por 20 min. (Nacir et al., 1989), lavados com solução de PBS estéril, para a retirada do excesso de hipoclorito de sódio, com posterior contagem e padronização do inóculo em câmara de Neubauer.

Vacinas - A amostra vacinal empregada foi a estirpe lentogênica LaSota, do vírus da doença de Newcastle (VDN). A determinação do título infectante em embrião $\left(E I D_{50}\right)$, da estirpe vacinal em estudo, foi feita segundo 0 método de Reed e Muench (1938): $\operatorname{EID}_{50}$ (LaSota) $=10^{8,0} /$ $0,1 \mathrm{ml}$. A padronização do inóculo vacinal seguiu a metodologia empregada por Paulillo (1980, 1984, 1989).

Exames anátomo-histopatológicos - Decorridos 32 dias da infecção (DAl) do Cryptosporidium ( $42^{\circ}$ dia de vida dos animais), $50 \%$ das aves de cada grupo foram necropsiadas para exames anatomopatológicos. As alterações macroscópicas foram anotadas e colhidos, em formol a $10 \%$, fragmentos de traquéia e bursa de Fabricius. Exames histopatológicos foram realizados em cortes (5 $\mathrm{mm}$ ), corados pelo método da hematoxilina-eosina.

Tabela 1 - Distribuição da aves em grupos experimentais

\begin{tabular}{|c|c|c|c|c|c|c|c|}
\hline \multirow{3}{*}{ Grupo } & \multirow{3}{*}{ № de aves* } & \multicolumn{3}{|c|}{ Oocistos do Cryptosporidium baileyi } & \multicolumn{3}{|c|}{ Vacinação } \\
\hline & & \multirow[t]{2}{*}{ Dose } & \multicolumn{2}{|c|}{ Inoculação } & \multirow[t]{2}{*}{ Amostra vacinal } & \multicolumn{2}{|c|}{ Inoculação } \\
\hline & & & Via & Idade (dias) & & Via & Idade(dias) \\
\hline 1 & 16 & $1 \times 10^{3}$ & Intratraqueal & 10 & LaSota & Ocular & 14 \\
\hline II & 16 & $1 \times 10^{5}$ & Intratraqueal & 10 & LaSota & Ocular & 14 \\
\hline III & 16 & $1 \times 10^{7}$ & Intratraqueal & 10 & LaSota & Ocular & 14 \\
\hline IV & 16 & $1 \times 10^{3}$ & Oral & 10 & LaSota & Ocular & 14 \\
\hline V & 16 & $1 \times 10^{5}$ & Oral & 10 & LaSota & Ocular & 14 \\
\hline VI & 16 & $1 \times 10^{7}$ & Oral & 10 & LaSota & Ocular & 14 \\
\hline VII & 16 & Placebo & Oral & 10 & LaSota & Ocular & 14 \\
\hline VIII** & 16 & Placebo & Oral & 10 & Placebo & Ocular & 14 \\
\hline
\end{tabular}

* coprologicamente negativas para C. baileyi; ${ }^{* *}$ grupo testemunho (não infectado e não vacinado) 
Colheita de sangue - Foram colhidas 256 amostras de sangue a partir do 13 o dia de idade dos animais (50\% das aves de cada grupo), com intervalos regulares de sete dias; foram realizadas quatro colheitas no total.

Os soros colhidos foram previamente inativados a $56^{\circ} \mathrm{C}$, por 30 min., para remoção de inibidores inespecíficos da hemaglutinação, de acordo com Phillips (1973), colocados em frascos de vidro de $5 \mathrm{ml}$ estéreis e armazenados em congelador a $-20^{\circ} \mathrm{C}$ até o momento do uso.

Exames sorológicos - Em todos os soros obtidos na fase experimental foi realizada a pesquisa de anticorpos $\mathrm{HI}$, com antígenos vivos contendo $4 \mathrm{UHA}$. Foi utilizada a microtécnica preconizada por Cunningham (1971).

Desafio - Aos 43 dias de vida dos animais, 50\% das aves de cada grupo foram desafiadas com uma estirpe velogênica viscerotrópica do VDN. Duzentos microlitros da suspensão do vírus contendo $10^{8,0} \mathrm{EID}_{50} / 0,1 \mathrm{ml}$ foram administrados por via óculo-nasal, de acordo com o preconizado pelo "National Research Council" (1971). Após o desafio, as aves foram observadas, diariamente, durante 15 dias, para registro dos sinais clínicos (morbidade) e da mortalidade.

Análise estatística - Utilizou-se um delineamento inteiramente casualizado, com oito tratamentos (lotes) e quatro repetições com quatro aves por parcela. Para comparação dos títulos de anticorpos $\mathrm{HI}$ e dos índices percentuais de proteção ao desafio nos diferentes grupos, aplicou-se um modelo de análise de variância descrito por Steel e Torrie (1960).

Nos casos em que foram constatadas diferenças significantes, foram executados contrastes, através do método de Tukey, ao nível de $5 \%$ de probabilidade.

\section{Resultados}

Os grupos inoculados com o C. baileyi apresentaram, na bursa de Fabricius, lesões macroscópicas caracterizadas por atrofia e leve hiperemia, além da presença, em algumas aves, de exsudato caseoso preenchendo a luz desse órgão. No sistema respiratório das aves dos lotes inoculados com o Cryptosporidium, via intratraqueal, existiam lesões somente na traquéia, as quais se caracterizavam pela presença de muco e leve hiperemia.

Em todos os lotes inoculados com o $C$. baileyi foi observada, na bursa de Fabricius, atrofia leve com rarefação de células linfóides, mais evidente na medular dos folículos. Lesões caracterizadas por infiltrado leve de células mononucleares e hiperplasia de células epiteliais e de folículos linfóides foram encontradas na traquéia de aves dos grupos inoculados com o parasito, via intratraqueal. Estágios endógenos do $C$. baileyi não foram observados nos fragmentos de tecidos submetidos a exame histopatológico. Os grupos que não foram inoculados com o C. baileyinão apresentaram lesões microscópicas.

As médias geométricas dos títulos de anticorpos $\mathrm{HI}$ dos soros das aves em período experimental (expressas em logaritmo de base 2) nos diferentes grupos estão na Tabela 2.

Tabela 2 - Médias geométricas dos títulos de anticorpos inibidores da hemaglutinação $(\mathrm{HI})$ dos soros das aves em período experimental (expressas em logaritmo de base 2) nos diferentes grupos

\begin{tabular}{lllll}
\hline & \multicolumn{4}{c}{ Médias geométricas dos títulos de $\mathrm{HI}\left(\mathrm{Log}_{2}\right)$} \\
\hline Grupo & \multicolumn{4}{c}{ Período experimental (idade em dias) } \\
\cline { 2 - 5 } & 13 & 20 & 27 & 34 \\
\hline I & $3,31 \mathrm{a}$ & $1,00 \mathrm{a}$ & $4,87 \mathrm{a}$ & $3,87 \mathrm{a}$ \\
II & $3,23 \mathrm{a}$ & $1,50 \mathrm{a}$ & $6,50 \mathrm{a}$ & $3,13 \mathrm{a}$ \\
III & $2,83 \mathrm{a}$ & $1,50 \mathrm{a}$ & $6,62 \mathrm{a}$ & $5,12 \mathrm{a}$ \\
IV & $3,38 \mathrm{a}$ & $1,50 \mathrm{a}$ & $3,62 \mathrm{ab}$ & $3,37 \mathrm{a}$ \\
V & $2,75 \mathrm{a}$ & $1,12 \mathrm{a}$ & $4,00 \mathrm{a}$ & $3,50 \mathrm{a}$ \\
VI & $2,62 \mathrm{a}$ & $1,00 \mathrm{a}$ & $4,25 \mathrm{a}$ & $3,87 \mathrm{a}$ \\
VII & $1,37 \mathrm{a}$ & $0,37 \mathrm{a}$ & $4,62 \mathrm{a}$ & $1,75 \mathrm{a}$ \\
VIII & $2,37 \mathrm{a}$ & $0,00 \mathrm{a}$ & $0,00 \mathrm{~b}$ & $0,00 \mathrm{a}$ \\
\hline F & $0,26 \mathrm{NS}$ & $0,91 \mathrm{NS}$ & $6,97^{*}$ & $1,73 \mathrm{NS}$ \\
\hline
\end{tabular}

*: significativo ao nível de $5 \%$ de probabilidade; NS: não significativo ao nivel de $5 \%$ de probabilidade.

Médias seguidas por letras iguais, dentro da mesma coluna, não diferem entre si, pelo teste de Tukey, ao nível de $5 \%$ de probabailidade.

Analisando a Tabela 2, observa-se que todos os lotes vacinados no $14^{\circ}$ dia de vida (Grupos I a VII) responderam ao estímulo antigênico, produzindo anticorpos $\mathrm{HI}$, com diferença estatisticamente significativa $(P<0,05)$ apenas no grupo IV, aos 27 dias de idade das aves. No grupo testemunho, como era de se esperar, não se detectou resposta sorológica ao antígeno vacinal.

Os resultados da prova com vírus virulento mostraram $100 \%$ de sobrevivência nos lotes inoculados com o $C$. baileyi. Comportamento imunitário semelhante foi observado no lote que recebeu apenas o inóculo vacinal (Grupo VII), notando-se um percentual de proteção ao desafio de $87,5 \%$. No grupo testemunho foi constatado que $87,5 \%$ das aves sucumbiram ao desafio. À observação clínica e à necroscopia, apresentaram sinais clínicos e lesões sugestivos da enfermidade de Newcastle (forma velogênica viscerotrópica).

\section{Discussão}

A presença de lesões macroscópicas na traquéia, caracterizadas por presença de muco e leve hiperemia, em frangos de corte inoculados, via intratraqueal, mostra que o C. baileyi, como sugerido por Blagburn et al. (1987), pode ser considerado como um dos agentes etiológicos do complexo respiratório das aves. Já as lesões microscópicas da traquéia, encontradas aos 32 DAl, caracterizam uma fase de reação tecidual posterior à infecção, com predominância de células mononucleares. A propósito, 
Blagburn et al. (1987) e Goodwin et al. (1988) estudando criptosporidiose respiratória em frangos de corte, também encontraram lesões microscópicas de traquéia na fase aguda da doença que se caracterizavam pela presença de hiperplasia e hipertrofia epitelial, perda de cílios, excesso de muco e infiltração de células mono e polimorfonucleares na lâmina própria e entre o epítélio.

De outra parte, a presença de exsudato caseoso na bursa de Fabricius está relacionada à infecção pelo Cryptosporidium (Meireles et al., 1995). As outras lesões macroscópicas, observadas na bursa de Fabricius, como atrofia e hiperemia são inespecíficas, embora as mesmas possam estar relacionadas à infecção pelo Cryptosporidium. Lesões microscópicas na bursa de Fabricius, observadas neste ensaio, aos 32 DAl, consistiram basicamente em atrofia folicular leve, que foi também observada por Levy et al. (1988), aos 8 e 16 DAl, em pintos livres de patógenos específicos inoculados com o $C$. baileyi, aos cinco dias de idade. Nesse mesmo experimento, também aos 8 e $16 \mathrm{DAl}$, foi observado um efeito sinérgico entre o vírus vacinal da doença de Gumboro e o C. baileyi na atrofia dos folículos linfóides da bursa de Fabricius, quando da inoculação dos animais com ambos os agentes, respectivamente, aos quatro e cinco dias de idade.

A ausência de estágios endógenos do $C$. baileyi no epitélio da bursa de Fabricius e traquéia das aves examinadas, aos 43 dias de idade (32 DAl), se deve ao fato de que o período patente da cepa utilizada, no presente experimento, se situa por volta de $18 \mathrm{DAl}$ (Meireles et al., 1995).

Nos exames sorológicos realizados (Tabela 2), em linhas gerais, não foram constatadas diferenças estatisticamente significativas $(P>0,05)$ entre os lotes inoculados com o parasito (Grupos I a VI) e o lote que recebeu apenas o inóculo vacinal (Grupo VII), evidenciando-se, assim, que o $C$. baileyi não interferiu na resposta sorológica induzida pela vacinação contra a doença de Newcastle. Já Blagburn et al. (1987), pesquisando a influência do $C$. baileyi na resposta imune de frangos de corte vacinados contra a doença de Newcastle, também não encontraram interferência do parasito na produção de anticorpos induzida pela vacina inativada, mas sim na hipersensibilidade tardia medida por inoculação de tuberculina na barbela de aves infectadas, via intratraqueal.

Na prova de desafio também não foram verificadas diferenças estatisticamente significativas $(P>0,05)$ entre os grupos I a VI e o grupo VII, o que vem enfatizar que não houve interferência da infecção pelo $C$. baileyi na proteção conferida pela vacina contra uma estirpe virulenta do VDN.

No presente trabalho, de um modo geral, parece que os resultados obtidos foram influenciados pelo alojamento das aves em gaiolas. Nesse tipo de criação, as aves não são expostas à reinfecção maciça e constante por milhões de oocistos esporulados, fato este que associado a fatores ambientais como estresse, presença de outros agentes patogênicos, entre os quais a Escherichia coli, poderia agravar ainda mais a infecção, exacerbandose assim o papel patogênico do $C$. baileyi no complexo respiratório das aves e no desenvolvimento de imunidade nessa espécie.

Pelos resultados apresentados pode-se concluir que 0 C. baileyi não interferiu na resposta imune de frangos de corte vacinados contra a doença de Newcastle, a despeito de haver, neste experimento, atrofia folicular leve na bursa de Fabricius das aves infectadas.

\section{Abstract \\ Influence of experimental infection with Cryptosporidium baileyi on the immune response of broiler chickens to Newcastle disease vaccination}

Broiler chickens raised in cages were inoculated by the oral or tracheal route with Cryptosporidium baileyi oocysts, with variation in infective doses for histopathologic evaluation and its influence in broilers immunity. One hundred twenty eight birds were divided in 8 groups with 4 replicates and 4 birds each replicate. When birds were 10 day old, they were inoculated with $10^{3}, 10^{5}$ or $10^{7}$ oocysts, followed by vaccination with LaSota strain of Newcastle disease virus (NDV), by the ocular route, at 14 days of age. For analysis of humoral immune response were used hemagglutination inhibition test in serum samples and the challenge protection test with velogenic viscerotropic strain of NDV, at 43 days of age. Macroscopic and microscopic lesions were evaluated in trachea and bursa of Fabricius. In the bursa of Fabricius were found mild mucosal hyperemia, caseous core filling the lumen, mild atrophy of follicles, besides infiltration of lymphocytes and plasma cells in the lamina propria. Tracheal lesions seen were presence of mucus, mild hyperemia, epithelial and submucosal lymphoid follicles hyperplasia in broilers inoculated by the tracheal route. Results of hemagglutination inhibition test and challenge protection test showed no interference in birds immune response.

Key words: Cryptosporidium baileyi; broiler chickens; immunity

\section{Agradecimentos}

Aos técnicos de laboratório Antonio José dos Santos e Aparecida Rodrigues Batista pelo auxílio prestado no desenvolvimento desta pesquisa.

\section{Referências bibliográficas}

Arrowood MJ, Sterling CR 1987. Isolation of Cryptosporidium oocysts and sporozoites using discontinuous sucrose and isopycnic percoll gradientes. J Parasitol 73: 314-319. 
Blagburn BI, Lindsay DS, Giambrone JJ et al. 1987. Experimental cryptosporidiosis in broiler chickens. Poultry Sci 66:442449.

Cunningham $\mathrm{CH}$ 1971. Virologia practica, 6 ed., Acribia, Zaragoza, $260 \mathrm{pp}$.

Dhillon AS, Thacker HL, Dietzer AV et al. 1981. Respiratory cryptosporidiosis in broiler chickens Avian Dis 25: 747751.

Fernández A, Quezada M, Gómez MA et al. 1990. Cryptosporidiosis in chickens from southern Spain. Avian Dis 34: 224-227.

Goodwin MA, Latimer KS, Brown J et al. 1988. Respiratory cryptosporisiosis in chickens. Poultry Sci 67: 1684-1693.

Itakura C, Goryo M, Umemura T 1984. Cryptosporidial infection in chickens. Avian Pathol 13: 487-499.

Levy MB, Ley DH, Barnes HJ et al. 1988. Experimental cryptosporidiosis and infectious bursal disease virus infections on specific-pathogen-free chickens. Avian Dis 32: 803-811.

Lindsay DS, Blagburn BL, Sundermann CA et al. 1988. Effect of broiler chicken age on susceptibility to experimentally induced Cryptosporidium baileyiinfection. Am J Vet Res 49: 1412-1414.

Meireles MV, Figueiredo PC 1992. Isolamento e identificação do Cryptosporidium baileyi, Current et al. (Apicomplexa: Cryptosporidiidae) em frangos de corte. Rev Bras Parasitol Vet 1,2: 125-130.

Meireles MV, Paulillo AC, Costa AJ et al. 1995. Correlação entre Toxoplasma gondii e Cryptosporidium baileyi em frangos de corte experimentalmente infectados. Rev Bras Parasitol Vet 4: 109-116.

Naciri M, Mazzella O, Coudert F 1989. Interactions cryptosporidies-virus sauvage ou vaccinal de la maladie de Marek chez le poulet. Rec Med Vet 4: 383-387.

National Research Council 1971. Subcomittee on Avian Diseases. Methods for examining poultry biologics and for identifying and quantifying avian pathogens. National Academy of Sciences, Washington, D.C., 320 pp.

Papadopoulou C, Xylouri E, Zisides N 1988. Cryptosporidial infection in broiler chickens in Greece. Avian Dis 32: 842843.

Paulillo AC 1980. Doença de Newcastle: Estudo experimental da resposta imune às estirpes vacinais $B$, e LaSota. Dissertação de Mestrado em Microbiologia, Instituto de Ciências Biomédicas, Universidade de São Paulo, São Paulo, 84 pp.

Paulillo AC 1984. Estudo experimental da resposta imunitária às vacinas inativada (oleosa) e viva (amostra LaSota) contra a doença de Newcastle. Tese de Doutorado em Microbiologia, Instituto de Ciências Biomédicas, Universidade de São Paulo, São Paulo, 129 pp.

PaulilloAC 1989. Avaliação da resposta imune e da performance zootécnica de poedeiras vacinadas experimentalmente contra a doença de Newcastle. Tese de Livre Docência em Ornitopatologia, Faculdade de Ciências Agrárias e Veterinárias, Jaboticabal, Universidade Estadual Paulista, 116 pp.

Phillips JM 1973. Vaccination against Newcastle disease: an assessment of haemagglutination inhibition titres obtained from field samples. Vet Rec 93: 577-583.

Randall CJ 1982. Cryptosporidiosis of the bursa of Fabricius and trachea in broilers. Avian Pathol 11: 95-102.

Reed LJ, Muench H 1938. A simple method of estimating percent endpoints. Amer J Hyg 27: 493-497.

Steel RGD, Torrie JH 1960. Principles and procedures of statistics. McGraw-Hill Book Company, New York, 481 pp. 